\title{
O futebol e as ditaduras nos tempos do Condor
}

\author{
Football and Dictatorships in Condor Times
}

\author{
Augusto Sarmento-Pantoja \\ Universidade Federal do Pará/Brasil \\ Doutor da Teoria e História da Literatura, UNICAMP \\ augustos@ufpa.br
}

\begin{abstract}
RESUmo: 0 presente estudo propõe analisar o filme Memórias do Chumbo: o futebol nos tempos do Condor, de Lúcio de Castro, articula o terrorismo de estado às ditaduras no Brasil, Uruguai, Argentina e Chile, associando-os a algumas representações do controle estatal no futebol. Observamos nelas como os mecanismos de silenciamento da violência e do terror são evidenciados. Articularemos as investidas das ditaduras contra suas seleções de futebol e as diversas intervenções sobre esse esporte para desviar os olhares para o futebol, deixando livres ou minimizando as atenções sobre as ações terroristas da ditadura. Teremos tanto no Brasil, quanto na Argentina, um alto investimento por parte da ditadura para que o Brasil se sagrasse campeão de 1970 e que a Argentina sediasse e fosse campeã do mundial de 1978. Buscamos compreender, nesse estudo, o papel da ditadura brasileira como a fomentadora dos demais regimes, colaborando com os países do Cone Sul por meio da Operação Condor.
\end{abstract}

Palavras-Chave: Operação Condor; Futebol; Ditadura; Copa do Mundo.

ABSTRACT: The present study proposes to analyze the film Memórias do Chumbo: o futebol nos tempos do Condor, by Lúcio de Castro, articulates state terrorism to dictatorships in Brazil, Uruguay, Argentina and Chile, associating them with some representations of the state's control in football. We see in them how the mechanisms of silencing violence and terror are evidenced. We will articulate the attacks of the dictatorships against their football teams and the various interventions on this sport to divert the eyes to the football, leaving free or minimizing the attention on the terrorist actions of the dictatorship. In both Brazil and Argentina, we will have a high investment by the dictatorship for Brazil to become champion of 1970 and Argentina to host and be the champion of the 1978 World Cup. We seek to understand, in this study, the role of the Brazilian dictatorship as the promoter of the other regimes, collaborating with the countries of the Southern Cone through Operation Condor.

KEYWoRDS: Operation Condor; Football; Dictatorship; World Cup. 


\section{INTRODUÇÃO}

Fazem parte desse estudo um conjunto de reportagens produzidas pela rede de esportes ESPN, tituladas Memórias do Chumbo: o futebol nos tempos do Condor, com direção do jornalista e historiador Lúcio de Castro. Essas matérias, compreendidas como documentários, nos mostram como a chamada Operação Condor, uma parceria política e militar entre os governos do Brasil, Argentina, Chile, Uruguai, Paraguai, Bolívia, Equador e Peru, ${ }^{1}$ para ampliar o controle e a repressão nos anos de 1960, 1970 e $1980,{ }^{2}$ que atingiram vários setores da sociedade, inclusive o futebol e as seleções daqueles países. 0 projeto, que incluía o financiamento e treinamento de agentes das ditaduras na América do Sul, era mantido pelos Estados Unidos, por meio da CIA (Central Intelligence Agency). Os documentários revelam como as ditaduras no cone sul foram extremamente cooperativas entre si, em nome do desenvolvimento de seus projetos autoritários baseados na Doutrina de Segurança Nacional, como destaca J. Patrice McSherry, ao definir que

La Operación Cóndor fue un sistema secreto de inteligencia y operativos [...] mediante el cual los Estados militarizados de América del Sul compartieron datos de inteligencia y capturaron, torturaron $\mathrm{y}$ ejecutaron opositores políticos en los territorios de otros países [...] La Operación Cóndor encarnaba un concepto estratégico clave de la Doctrina de la Seguridad Nacional de la Guerra Fría. ${ }^{3}$

A Guerra Fria, sem dúvida foi o aríete para o financiamento das ditaduras na América Latina, já que era de interesse dos norte-americanos manter o domínio político e militar em seu continente, uma vez que, após a Segunda Guerra Mundial, o mundo ficou polarizado e os territórios disputados pelo capitalismo e o socialismo tinham braços e pernas espraiados. Na América Latina, A Revolução Cubana (1953-1959) tornou-se o primeiro vulto de ameaça ao poder norteamericano e com isso o alinhamento de Cuba à União Soviética, e a esperança vermelha para o continente, amplamente combatida pelo bloco capitalista. Como

\footnotetext{
${ }^{1}$ McSHERRY. Los Estados depredadores, p. 28-29. "Los miembros clave del sistema fueron los regímenes de Argentina, Chile, Uruguay, Paraguay, Bolivia y Brasil, a los cuales se unieron posteriormente el Ecuador y el Perú, en papeles menos prominentes".

2 McSHERRY. Los Estados depredadores, p. 28. "En los decenios de 1960, 1970 y 1980, las fuerzas armadas, con el respaldo de los Estados Unidos, realizaron golpes militares en toda América Latina, procediendo a obliterara las fuerzas de izquierda y extirpar las ideas izquierdistas".

${ }^{3}$ McSHERRY. Los Estados depredadores, p. 25.
} 
consequência da vitória cubana, o anseio de fazer a revolução em outros países latino-americanos, cresce e abre espaço para que os ideais esquerdistas se proliferem, o que potencializou a atuação direta e indireta nos governos do continente por parte dos EUA, que fomenta a criação de governos alinhados aos blocos capitalistas.

Neste sentido, governos que não estavam alinhados a uma política capitalista desenvolvimentista, foram os primeiros a serem combatidos e destituídos. Foi o que ocorreu com governo Paraguaio, historicamente marcado por governos militares, com características ditatoriais, quando em 1949 assume Federico Chaves que fica no poder até sua deposição em 1954, quando o General Alfredo Stroessner, instalando o estado de sítio permanente, suspendendo o mesmo apenas nas eleições seguintes (1958, 1963, 1973, 1978, 1983 e 1988). A ditadura paraguaia se encerra em 1989, quando Stroessner será deposto para a instalação de um governo democrático, mas também liderado por um militar.

Um dos motivos que levaram a instalação da ditadura do general Stroessner foi a aproximação de Federico Chaves ao governo de Juan Domingos Perón, da Argentina. 0 governo de Perón, iniciado em 1946, em poucos anos do primeiro mandato, passa a colocar as assas de fora e começa uma campanha de autopromoção Argentina, como sendo a terceira via, uma opção entre o capitalismo norte-americano e o socialismo soviético. Esse foi um dos motivos que levaram a deposição de Perón em 1955, já no seu segundo mandato. A instauração do governo militar por meio da Revolução Libertadora abre um ciclo de combate ao peronismo, que provocou a realização de eleições, mas com proibição desse partido. Mesmo sem os peronistas, foram anos conflituosos, principalmente quando algum governo tentava liberá-los. Desse modo, vemos que o peronismo vai ser uma forte condição para o fomento norte-americano de governos ditatoriais.

No caso brasileiro, vimos que o bloco capitalista passa a formalizar preocupação quando João Goulart assume o poder diante da renúncia de Jânio Quadros, em 1961. Os anos que se seguiram foram bastante conturbados, principalmente por conta do discurso reformista de João Goulart, associado a uma evidente instabilidade militar, com insurgências das baixas patentes, o que colaborou com a organização dos generais e a impetração do golpe sob a alegação de que o presidente estava implementando reformas comunistas. A deposição de 
João Goulart e instalação de um governo provisório, culminando na eleição indireta dos vários generais que puseram em prática a Doutrina de Segurança Nacional e a manutenção de governos autoritários, que tinham o auxílio norte-americano para a formação dos agentes de repressão. Vejamos uma passagem de um documento americano sobre a troca de informações e a limitação de Brasil e Argentina no assessoramento dos países menores ao combate aos movimentos de esquerda:

Intergovernmental Cooperation. Southern Cone security forces undoubtedly coordinate their counterterrorist efforts insofar as information exchanges are concerned, and Argentina and Brazil may provide limited training and advisory service to their smaller neighbors. Over two years ago, security officials from all the Southern Cone countries except Brazil met in Buenos Aires and reportedly formalized arrangements to facilitate information exchanger and the movement of security officials on government business. ${ }^{4}$

O fragmento acima foi retirado dos chamados arquivos desclassificados do FBI, citado pela Comissão Nacional da Verdade. Consideramos, por ele, clara a participação do Brasil e o seu protagonismo, juntamente a Argentina, para realizar treinamento, mesmo que "may provide limited training and advisory service to their smaller neighbors". Essa falta de condições para realizar os treinamentos e a assessoria, evidencia o papel norte-americano, como o detentor do know-how para treinar e assessorar esses dois países, capacitando-os para atuarem, a posteriori, como reprodutores de tais técnicas.

A Operação Condor (Plan Cóndor, Operativo Cóndor, OC), nasce de uma reunião convocada pela ditadura civil-militar de Augusto Pinochet, no Chile, como destaca o relatório da Comissão Nacional da Verdade (CNV), de 2014, ao salientar que "O convite era assinado pelo coronel Manuel Contreras, chefe da Direção de Inteligência Nacional (DINA), o órgão central de repressão da ditadura chilena" (CNV, 2014, p. 221). Era evidente que a ditadura Chilena estava procurando movimentar os países latinos em busca dessa coalizão, que já existia, mas não com

\footnotetext{
${ }^{4}$ Tradução livre do documento: "Cooperação Intergovernamental. As forças de segurança do Cone Sul, sem dúvida, coordenam esforços antiterroristas, no que diz respeito à troca de informações. $\mathrm{E}$ compreende que a Argentina e o Brasil podem fornecer serviços limitados de treinamento e assessoria aos seus vizinhos menores. Há mais de dois anos, funcionários de segurança de todos os países do Cone Sul, exceto o Brasil, se encontraram em Buenos Aires e, segundo informaram, formalizaram os arranjos para facilitar o intercâmbio de informações e o movimento de funcionários de segurança nas questões governamentais." Arquivos Desclassificados EUA. Operação Condor, FBI, 19/7/1976, p. 3. Disponível em: https://bit.ly/2G3fXyE.
} 
a mesma estrutura da Operação Condor. O Brasil, querendo manter seu protagonismo no Cone Sul, terá uma posição defensiva quanto a esse acordo, pelo menos no início, tanto que:

O jornalista Luiz Cláudio Cunha revelou que o governo Geisel (1974-79) enviou para a reunião de fundação [da Operação Condor] dois oficiais do CIE, ambos comandantes veteranos de operações de repressão à guerrilha do Araguaia (ver capítulo 14). 0 tenente-coronel Flávio de Marco e o major Thaumaturgo Sotero Vaz participaram da reunião em Santiago na qualidade de observadores e, seguindo instruções superiores, não assinaram a ata da reunião. ${ }^{5}$

As ordens recebidas de serem somente observadores e de não assinarem tal ata, revela como o governo brasileiro recebeu com reserva a criação da operação, pois ela poderia colocar o protagonismo na região nas mãos dos chilenos. A CNV analisou outros documentos que evidenciam a participação brasileira e que ela em momento algum pode ser classificada como alegórica, pelo contrário, o Brasil esteve presente em várias outras reuniões e fez parte de várias ações cooperadas da OC, vejamos abaixo:

Documentos desclassificados pelo Governo dos Estados Unidos evidenciam que, efetivamente, o Brasil esteve presente em diferentes reuniões da Condor. Um desses documentos é o resumo da CIA intitulado Weekly Summary, de 2 de julho de 1976, parcialmente desclassificado, que informa sobre uma reunião de trabalho em Santiago do Chile, em junho de 1976, da qual participaram os serviços de inteligência do Brasil, juntamente com representantes da Argentina, Bolívia, Chile, Uruguai e Paraguai. Nesse encontro foi decidido o estabelecimento de um banco de dados computadorizado sobre pessoas suspeitas de "subversão". ${ }^{6}$

Sem dúvida, essa aliança ficou bem além dos bancos de dados, tanto que os nomes mais representativos da repressão brasileira naquela época, foram os responsáveis por comandar a Operação Condor em Brasília, como destaca a comissão da verdade brasileira:

Após comandar o DOI-CODI do II Exército, na Rua Tutoia, em São Paulo, entre 1970 e 1974, durante o governo Médici (1969-1974), o major Carlos Alberto Brilhante Ustra foi promovido a coronel e transferido

\footnotetext{
${ }^{5}$ CNV. Relatório, p. 223.
}

${ }^{6}$ CNV. Relatório, p. 223. 
para Brasília, como chefe do Setor de Operações do CIE, posto que ocupou entre dezembro de 1974 e dezembro de 1977. Ustra foi sucedido no Setor de Operações do CIE, braço brasileiro da Condor, pelo então coronel José Antônio Nogueira Belham, que chefiava como major o DOI-CODI do I Exército, na Rua Barão de Mesquita, no Rio de Janeiro, à época do sequestro, tortura e morte do ex-deputado Rubens Paiva. ${ }^{7}$

Comandar a OC parecia ser um prêmio pelos serviços prestados nos DOICODE, de São Paulo e Rio de Janeiro, aos mais eficientes braços da repressão brasileira, por isso a escolha de Ustra e Belham para o cargo, pois o comando necessitava de militares experientes, por conta das múltiplas relações com os países vizinhos. 0 pesquisador Aluízio Palmar nos mostra como essas relações aconteciam. Em sua pesquisa, ele relata um episódio sobre a fronteira de Itaipu, que nos revela a arquitetura da Operação Condor no Brasil e como a cooperação na tríplice fronteira não se limitava apenas a banco de dados e informantes. Vejamos o que ele descreve:

A participação de Itaipu na Operação Condor pode ser comprovada em diversos expedientes que se encontram no arquivo da Polícia Federal de Foz do Iguaçu, como, por exemplo, o informe 031/76, de 15/12/76, enviado pela AESI brasileira à sua similar paraguaia. Atendendo ao pedido de seus colegas paraguaios, os chefes do serviço reservado do general Costa Cavalcanti puseram os seus agentes ao encalço do médico ortopedista e dirigente do Movimento Popular Colorado (Mopoco) Agostín Goiburú Gimenez.

Dois meses após a AESI/Itaipu ter enviado o relatório aos militares paraguaios, Goiburú, que estava asilado na Argentina e costumava vir a Foz do Iguaçu visitar os amigos, desapareceu. Anos mais tarde o professor paraguaio Martim Almada descobriu durante pesquisa no arquivo secreto da polícia de Stroessner que Agostín Goiburú havia sido sequestrado e levado para o Paraguai, onde foi torturado até a morte no Regimento Escolta Presidencial, em Assunção. ${ }^{8}$

O sequestro de militantes de esquerda foi uma prática muito comum na Operação Condor, mas não se limitou aos militantes. 0 cerco opressivo teve uma amplitude tamanha, capaz de atingir setores da sociedade civil nunca imaginados, como é o caso do esporte, em especial, o futebol. A série Memórias do Chumbo: o futebol nos tempos do Condor, ${ }^{9}$ nos revela isso. Formada por quatro filmes, descreve situações e traz à tona, cenas intrigantes do papel da Operação Condor,

\footnotetext{
${ }^{7}$ CNV. Relatório, p. 224.

${ }^{8}$ PALMAR. Onde foi que vocês enterraram nossos mortos?, p. 88.

${ }^{9}$ Lançado em 2013, recebeu o prêmio Gabriel García Marques de Jornalismo, na Colômbia.
} 
na manutenção do sistema de repressão em cada país: Brasil, Argentina, Uruguai e Chile. Nesse estudo, nos deteremos ao filme sobre o Brasil, mas não deixaremos de lembrar alguns episódios fundamentais dos demais filmes.

\title{
O FUTEBOL BRASILEIRO E INTERVENÇÃO DITATORIAL
}

\author{
Noventa milhões em ação \\ Pra frente, Brasil, do meu coração \\ Todos juntos vamos \\ Pra frente, Brasil! Salve a seleção! \\ De repente, é aquela corrente pra frente, \\ Parece que todo o Brasil deu a mão \\ Todos ligados na mesma emoção \\ Tudo é um só coração. \\ Todos juntos vamos \\ Pra frente, Brasil, Brasil! Salve a seleção!10
}

A euforia do futebol brasileiro passa pelo fim dos anos dourados e pelo início dos anos de chumbo, já que a vitória nas Copas do Mundo de 1958 e 1962 fez do futebol um excelente instrumento de propagando governamental. Mesmo com a derrota em 1966, em uma Copa já sobre os reflexos da instalação do regime ditatorial de 1964, o futebol tem uma importância singular no esquema de controle das massas, pensado também pelo governo ditatorial. Era preciso controlar a paixão nacional e manipulá-la a favor do regime. A letra da música de Miguel Gustavo, "Pra frente, Brasil", evoca bem o modelo desejado pelo estado brasileiro, constituindo o futebol como a ligadura social responsável por ser de repente “aquela corrente pra frente / Parece que todo o Brasil deu a mão", prenúncio de que para a Copa de 1970, após o fracasso de 1966, é preciso que a sociedade deixe suas individualidades e se concentre em dar a mão ao outro, esquecer o que passou, esquecer o está acontecendo. Uma forma de usar o futebol como massa de manobra em nome do silenciamento e/ou mascaramento da realidade repressora, como será bem explorado anos depois por outro filme, "Pra frente, Brasil", de

${ }^{10}$ Composição de Miguel Gustavo, vencedor do concurso que elegia em 1970 o hino da seleção brasileira de 1970. No entanto, há evidências de que a música fora encomendada pela ditadura para ampliar o sonho nacionalista de felicidade. Apesar de vários analistas conceberem que a música foi feita para o mercado publicitário, se tornou a marca da conquista do tricampeonato, mas traz consigo a marca do autoritarismo, da amnésia coletiva da realidade política brasileira. 
1982, dirigido por Roberto Farias. Nele, a canção é mostrada pelo viés contraditório do discurso da repressão, que insiste em dizer que não teve nada a ver com os acontecimentos no entorno da Copa de 1970. 0 documentário, que analisamos aqui, inicia com uma apresentação dos anos que antecederam a ditadura militar e as confluências históricas, que potencializaram a criação dos regimes ditatoriais na América Latina, aos poucos mostra como o Brasil vive os primeiros anos da ditadura até chegar ao futebol, utilizado como matéria propagandística do regime. Muitos podem questionar os caminhos do documentário, mas não temos como deixar de lado a forma como a ditadura brasileira manipulou e monitorou o futebol. Como ilustração voltamos ao caso da música de Miguel Gustavo, o documentário, nos mostrou que a escolha, apesar de não ter sido encomendada pela ditadura, teve todo apoio do regime, por conta da afinação com os interesses dele, como declara Otávio Costa:

Uma coisa convergia para a outra a grande mola desse sucesso da Copa do Mundo foi a canção de Miguel Gustavo, "Pra frente, Brasil", pensa-se que foi parte de campanha nossa. Não! Não foi iniciativa nossa. Miguel Gustavo, nos procurou com a peça pronta, não fomos nós que mandamos fazer a peça. Peça pronta que um cliente tinha pedido para fundo musical de suas propagandas comercial, nos mostrou a peça e pediu ajuda na divulgação. E realmente a nossa participação, com a música de Miguel Gustavo, foi ajudar na divulgação dessa música. ${ }^{11}$

Não temos como deixar de levar em consideração o fato de que para o regime tudo aconteceu como um acaso, a sociedade civil. Neste caso, Miguel Gustavo, Zagallo, Pelé, Chacrinha, etc., foram decisivos para o êxito da ditadura, pois ajudaram deliberadamente a construir o discurso vencedor e reproduzir a amnésia sobre a realidade política brasileira, de repressão, sequestros, torturas e mortes.

Mas mesmo diante da euforia futebolística da primeira Copa do Mundo a ser transmitida ao vivo e em cores para todo o mundo (1970), a intromissão da ditadura sobre o futebol era bem clara, porém não iniciou com a campanha do México, a interferência da ditadura teve suas vitórias e derrotas. Entre as derrotas, temos o exemplo da preparação para a Copa de 1966, em Londres. Estávamos nos primeiros anos da ditadura, e o processo de preparação da seleção foi planejado dentro do discurso nacionalista de valorização do Brasil e das cores da nação, por

${ }^{11}$ CASTRO. Memórias do Chumbo (Brasil), 26’00". 
isso, foram convocadas quatro seleções (verde, amarelo, azul e branco), que percorreram cidades estratégicas, no projeto de controle das massas. A justificativa para tal insanidade era a de realizar uma preparação da seleção junto ao povo. A preparação caótica impõe uma derrota singular à seleção de 1966.

Para a Copa de 1970, o controle continua, mas a estratégia foi outra. Um dos nomes do futebol mais controlados foi o do técnico da seleção brasileira João Saldanha, que por conta de sua relação com a esquerda, foi destituído do cargo, pois teria sido considerado perigoso pelo fato de denunciar, em suas viagens para o exterior, a violência e a tortura da ditadura brasileira. Em reportagem alusiva ao centenário de João Saldanha, no jornal El País, o jornalista Breiller Pires relata que:

Apesar do sucesso e da popularidade como treinador, Saldanha não deixou de atacar a ditadura, principalmente após a ascensão do general Emílio Garrastazu Médici ao poder. 0 regime militar endureceu a repressão a integrantes do Partido Comunista. No fim de 1969, o assassinato de Carlos Marighella, um amigo de longa data, despertou de vez a ira do treinador da seleção. Ele montou um dossiê, em que citava mais de 3.000 presos políticos e centenas de mortos e torturados pela ditadura brasileira, e o distribuiu a autoridades internacionais em sua passagem pelo México na ocasião do sorteio dos grupos da Copa, em janeiro de 1970.12

Certamente Saldanha se tornou uma ameaça, pois poderia desbancar a luta contra a ameaça vermelha. Em entrevista concedida ao programa Roda Viva, da TV Cultura de São Paulo, João Saldanha explica como se deu o caminho de pressões, que culminaram na sua demissão da Seleção Brasileira:

A morte de Costa e Silva foi dada oficialmente no dia 14 de novembro daquele mesmo ano, de 1969, Em seguida veio um triunvirato, lembra, um do exército, um da marinha e um da aeronáutica... Bom! Não se incomodaram comigo, três meses depois, [...] entra esse cara, o Médici, mau, rancoroso, frio [...] maior assassino da história do Brasil! Ai eu já sabia! [...] porque com o Costa e Silva, teve o começo do AI-5 [...] Aí veio e começou a pressão! Inclusive eu sugeri para o Havelange, quando ele dizia pô João, pelo amor de Deus, pede demissão com e eles fizeram aquela chantagem do tal do exame médico do Toninho e do Escala, e o Escala estava todo arrebentado [...], mas o Toninho não tinha nada [...], cortaram o Toninho. Chamei aquele Zé Carlos do Cruzeiro, o que eles queriam? E o Havelange dizia: Pelo amor de Deus, chama o Dario, que agente fica bem com os homens. Eu dizia: Havelange não adianta se

${ }^{12}$ PIRES. Os 100 anos de João Saldanha, o técnico que atormentou a ditadura militar, El País, 03/07/2017. 
abaixar, quanto mais se abaixar mais eles vão malhar. E pra cima de mim! [...] Por que o negócio não era a seleção brasileira era atender o homem. ${ }^{13}$

Para Saldanha, a demissão se deu por conta da linha dura de Emílio Garrastazu Médici, pois tanto no Governo de Artur Costa e Silva como membros da junta militar que o sucedeu: General Aurélio de Lira Tavares, ministro do Exército; Almirante Augusto Rademaker, ministro da Marinha; e Brigadeiro Márcio Melo, ministro da Aeronáutica. Para Saldanha, esses presidentes aceitavam bem as suas escolhas como treinador, mas com a posse de Médici, as pressões eram tamanhas, tanto por parte do presidente, quanto da opinião pública, pois João Saldanha, o "João sem Medo", alcunha recebida de Nelson Rodrigues, não aceita atender à exigência de convocar o Dario, do Atlético. Para muitos, essa insubordinação seria o pretexto para a sua demissão, como vemos a seguir:

Dadá Maravilha foi convocado por Zagallo, mas não disputou nenhuma partida na Copa. Mais tarde, confidenciou que João Havelange, então presidente da CBD, teria admitido que despediu Saldanha por imposição de Médici. "O regime não admitia a possibilidade de um líder oposicionista tão expressivo como o Saldanha voltar do México consagrado e venerado pelo povo", conta o jornalista Carlos Ferreira Vilarinho, autor do livro "Quem derrubou João Saldanha". Em uma entrevista ao programa Roda Vida, em 1985, o próprio Saldanha resumiu o desenrolar de sua queda diante das pressões do governo. "Considero Médici o maior assassino da história do Brasil. Ele nunca tinha visto o Dario jogar. Aquilo foi uma imposição só para forçar a barra. Recusei um convite para jantar com ele em Porto Alegre. Pô, o cara matou amigos meus. Tenho um nome a zelar. Não poderia compactuar com um ser desses". ${ }^{14}$

A análise de Vilarinho sobre a possibilidade de consagração de Saldanha, também foi explorada pelo primeiro filme da série Memórias do Chumbo: o futebol nos tempos do Condor, não se limitando a esse fato, o filme explorou outros casos de intervenção antes, durante e depois da Copa, para somente depois enveredar por apresentar a Operação Condor. Inúmeros nomes e casos vieram à tona, entre eles a própria escolha de Zagallo, apresentada no documentário como um golpe de sorte, como o narrador Luis Alberto Volpe nos informa, e é endossado por José Bonetti, ao retratar o acaso que envolveu a escolha de Zagallo para dirigir a seleção

\footnotetext{
${ }^{13}$ SALDANHA. Entrevista, Roda Viva, 25/05/1987, 12'16".

${ }^{14}$ PIRES. Os 100 anos de João Saldanha, o técnico que atormentou a ditadura militar, El País, 03/07/2017.
} 
de 1970, pois a Confederação Brasileira de Desportos (CBD) havia escolhido para técnico Otto Glória, que vinha de Portugal vitorioso com o Benfica, tricampeão da Taça de Portugal e do Campeonato Português. Vejamos o seu relato: "fui ao América e não encontrei o Otto, a pedido do Dr. Passo, e por um acaso, e é essa a história, o Zagallo treinava o Botafogo, aonde? Na escola de educação física do exército, lá que nós nos reuníamos, e aí surgiu em um bom momento o nome do Zagallo".15 0 acaso é o nome desses tempos, o acaso decidiu o novo treinador da seleção, já formada por Saldanha e embalada pelas seis vitórias, nos seis jogos das eliminatórias. Foram apenas seis dias antes do embarque para o México, para que as certezas de Saldanha se concretizassem.

Mas as oportunidades para que o regime continuasse soberano continuavam explícitas, aos poucos a ação da ditadura vai ganhando novos contornos com a criação da Operação Condor. O documentário revela uma das diversas atividades de cooperação internacional no combate à subversão envolvendo o Brasil e o Uruguai, trata-se do sequestro do casal de militantes uruguaios, Univercindo Diaz e Lilían Celiberti, e os filhos da militante Camilo e Francesca. A ação da repressão chegou ao conhecimento público, graças a um telefonema anônimo de outro militante uruguaio no Brasil, Hugo Cores, secretário Geral do PVP (Partido por la Victoria del Pueblo) e principal dirigente político no Brasil, que naquela altura era o principal alvo da Operación Zapato Roto (como denominaram os uruguaios), por ser um importante denunciador das atrocidades da ditadura uruguaia destaca Ramiro José dos Reis, em pesquisa sobre o sequestro dos uruguaios. Vejamos o que o pesquisador nos apresenta sobre a denúncia:

O sinal de alerta desde Porto Alegre até a base de Paris foi imediatamente passado a Hugo Cores, que, por sua vez, acionou o jornalista Luiz Cláudio Cunha. Foi assim que no dia 17 de novembro de 1978, Cunha, chefe da sucursal da revista Veja no Rio Grande do Sul, recebeu um telefonema anônimo de São Paulo, em espanhol: una pareja $y$ dois niños uruguayos que viven em Porto Alegre están desaparecidos hace una semana. Após anotar os nomes e endereço, o jornalista foi informado que o termo "desaparecidos" significava "detenidos". ${ }^{16}$

Logo após a descrição do telefonema o pesquisador relata ainda que o jornalista procurou checar imediatamente a denúncia e, para isso, contou com o ${ }^{15}$ CASTRO. Memórias do Chumbo (Brasil), 16'06".

${ }^{16}$ REIS. Operação Condor e o sequestro dos uruguaios nas ruas de um porto não muito alegre, p. 97. 
fotojornalista da revista Placar, pertencente ao mesmo grupo jornalístico, Grupo Abril, para o acompanhar na investigação, pois o fotógrafo da Veja não se encontrava. Novo acaso, mas agora para desbaratar a Operação Zapato Roto. Justamente a troca do fotógrafo foi determinante, pois ele reconheceu um dos agentes do DOPS, o que possibilitou o desmanche da operação e a associação da mesma com o futebol. O fotojornalista João Batista Scalco, por ter realizado matérias, esportivas se depara com um ex-jogador do Internacional de Porto Alegre, trata-se de Orandir Portassi Lucas, vulgo "Didi Pedalada", denunciado por Universindo como um dos mais cruéis torturadores. Mas a denúncia não se limitou a Didi, Lilián nos conta no documentário sobre o envolvimento de um nome forte da repressão gaúcha, que acompanha toda a operação, o delegado do DOPS, Pedro Seelig, um dos mais importantes nomes da repressão brasileira, amante do futebol e grande torcedor colorado (Internacional), vejamos o depoimento de Lilián:

Desde o primeiro momento ele está presente, desde a detenção, é Seelig que me pede os documentos, é Seelig que me leva a delegacia, pela primeira vez, é Seelig que me leva a minha casa, é Seelig que decide que eu vá com os meus filhos, ou seja, ele está presente em todos os momentos. [...] Era a voz que decidia, toda a operação. [em momento de tortura Seelig também estava presente]. Sim, totalmente, sempre presente. ${ }^{17}$

O papel de Pedro Seelig na operação fica bem evidente. 0 trauma vivido pela militante se expressa pela onipresença do delegado, em todos os momentos de sua experiência no sequestro dos uruguaios. O filme de Lúcio de Castro traz o depoimento de Luiz Cláudio Cunha analisando como a falta de julgamento dos crimes cometidos contra a sociedade durante a ditadura revelam algumas aberrações, como o fato dos principais agentes da repressão, como Fleury, Ustra e Seelig não terem sido julgados pelos crimes cometidos.

O documentário termina o capítulo sobre o Brasil mostrando que, graças ao acaso, tivemos o privilégio de nos encontrar com sobreviventes da Operação Condor, uma raridade, pois na história latina dos anos de 1970, só temos notícia de quatro sobreviventes, Universino, Lilián, Camilo e Francesca, isso porque as ações promovidas pelos carcarás não ficaram na história, mas se mantêm na lembrança de familiares de quem foi pego, morto e comido pelo Condor.

${ }^{17}$ CASTRO. Memórias do Chumbo (Brasil), 45’53”. 


\section{MiRADAS DEL CONDOR}

Os outros três filmes que compõem a série Memórias do Chumbo: o futebol nos tempos do Condor, trazem outras experiências e outros complexos das ditaduras vividas por nossos vizinhos do cone sul: Argentina, Uruguai e Chile. Por conta da extensão dos filmes e da riqueza de aspectos a serem analisados, não temos condições de dar conta de todos neste texto, mas vamos apresentar sucintamente pelo menos um aspecto de cada filme articulado ao autoritarismo e à resistência aos regimes ditatoriais que se instalaram na América Latina. Começamos com a manobra para a realização da Copa da Argentina em 1978, depois passamos à resistência no futebol uruguaio, para enfim encerrar com o caso do Estádio Nacional de Santiago, no Chile.

A história futebolística da Argentina não era tão brilhante como de seus hermanos brasileiros e uruguaios, não tinha sido campeã mundial, mas ficou marcada pelo vice-campeonato de 1930. Um trauma esportivo, que seria fundamental ser vencido. O filme inicia com o áudio, do tenente-general Jorge Rafael Videla - comandante-geral do exército argentino -, divulgado em cadeia nacional, em 23/03/1976, o qual informava:

Comunicado número um da junta dos comandantes gerais. Comunicamos à população que a partir desta data o país se encontra sob o controle operacional da junta de comandantes gerais e das forças armadas. Recomendamos a todos os habitantes o cumprimento rigoroso das disposições e diretrizes emitidas pelas autoridades militares de segurança ou policial e cuidado rigoroso para evitar ações e atitudes individuais ou em grupo que possam exigir a intervenção drástica da equipe de operações. ${ }^{18}$

Os comunicados se sucederam a diversas intervenções do governo sobre a população. No dia seguinte ao golpe, a junta militar faz um segundo comunicado bastante determinante e ao mesmo tempo esdrúxulo:

Comunicado número um, proíbe-se as reuniões nas ruas;

Comunicado número dois, proíbe-se fazer greve;

Comunicado número três, proíbe-se legislar;

${ }^{18}$ CASTRO. Memórias do Chumbo (Argentina), 00’42". 
Proíbe-se, proíbe-se, proíbe-se...

E comunicado número vinte e três, dizia-se: autoriza-se.

E o que se autorizava? Autorizavam-se as transmissões da partida de futebol da seleção argentina, que naquele dia, jogava na Polônia, contra a Polônia. A partir daquele momento a ditadura ficou claro que a ditadura sabia do que se tratava o futebol. ${ }^{19}$

A ditadura já no segundo dia deixa seu recado tanto no âmbito do autoritarismo, quanto na sabedoria sobre o futebol. A escolha da Argentina como sede da Copa de 1978, trouxe ânimo ao governo militar para transformar o evento no referendo ao poder ditatorial, principalmente com a confirmação do título. Há inúmeras especulações sobre as motivações políticas para a escolha das sedes, desde a primeira Copa em 1930 no Uruguai, passando pelo Brasil em 1950, no Chile em 1962, no México em 1970. Vários indícios nos levam a acreditar que aspetos políticos foram decisivos para a escolha das sedes não europeias. Uruguai é o primeiro caso, vemos a necessidade de criar um primeiro evento comparável aos jogos Olímpicos, mas que estivesse relacionado a um único esporte, que se apresentava naquele momento como uma grande aposta econômica, mas ficaria difícil realizá-lo na Europa, por conta das consequências da queda da bolsa de valores de New York, que afundou os mercados. Por isso, seria estratégico escolher uma sede que pudesse render lucros ao evento, daí o critério de escolher o Uruguai, já que ele era o campeão no futebol das duas últimas edições olímpicas, 1924 (Paris) e 1928 (Amsterdã). As chances de encontrarmos uma população empolgada com uma Copa em seu país eram grandes.

Vinte anos depois temos uma nova edição latino-americana, desta vez com o Brasil, passávamos por um momento de afirmação econômica com o governo de Djalma Dutra, com os acordos com os EUA e criação das primeiras refinarias de petróleo. Outra justificativa para a vinda da Copa para as Américas era a recente guerra mundial, que destruiu política, econômica e geograficamente os países europeus. Por fim, parece que os acontecimentos da Copa de 1938, que eliminaram o Brasil da final por conta de um pênalti a favor da Itália, podem ter pesado também na decisão. Com as Copas do Chile em 1962 e no México em 1970, parece que os motivos estão atrelados ao bom relacionamento econômico com os EUA e boa condição financeira dos países para sediar a Copa. Já a Argentina, a escolha nos

${ }^{19}$ CASTRO. Memórias do Chumbo (Argentina), 02'13". 
mostra uma tentativa de reafirmação da política antiperonista na época da escolha e a articulação com a ditadura argentina.

Há uma articulação entre o orgulho da vitória e a frustração em relação à ideia de que a Copa da Argentina, fora a Copa da ditadura e o time seria um discurso de afirmação do autoritarismo na América Latina, como já foi feita no caso brasileiro, com o uso político e propagandístico da Copa do México de 1970, em que o Brasil venceu. No caso da Argentina, o documentário articula a vitória a uma derrota social, pois escamoteia o conflito do rapto, do desaparecimento e da adoção de crianças filhas de militantes que lutaram contra a ditadura. Os dados apresentados são chocantes, havia na Argentina algo em torno de 500 centros de tortura, responsáveis pelo desaparecimento de milhares de militantes e pelo menos 500 crianças e 30.000 mortos.

O filme se fixa em dois polos, o primeiro na relação do futebol com a dúbia sensação de vitória e derrota, por conta da seleção argentina ter se tornado objeto de propaganda da ditadura; de outro um dos principais dramas vividos pelo povo argentino durante a ditadura, o sequestro de crianças filhas de militantes e sua entrega para adoção por famílias colaboradores do regime ditatorial. Este último aspecto vai tomar grande parte do filme e se dedicará a contar a história de Mariana Zaffaroni, uma dessas 500 crianças citadas na reportagem:

Meus pais eram uruguaios militavam nas associações de trabalhadores e estudantis, e quando começou a ditadura no Uruguai vieram para a argentina. Eu nasci aqui, em 1975. E, quando começou a ditadura, na Argentina, em 1976, eu tinha poucos meses. Sequestraram nós três e nos levaram a um centro de detenção, de onde fui levada pelo pai que me criou. Não se sabe o destino que eles tiveram. Suspeita-se que eles tenham sido levados para o Uruguai em um voo clandestino e que tenham sido assassinados lá, mas não há nenhuma prova disso.20

A escolha pela história de Mariana é providencial, pois com o fim da ditadura, sua imagem de bebê circula por todos os lugares e uma denúncia, transforma o caso de Mariana símbolo da luta das "Abuelas de Plaza de Mayo", pois assim como a avó de Mariana lutava para provar que a menina era sua neta, sequestrada e entregue para a adoção, centenas de outras avós acampavam a

\footnotetext{
${ }^{20}$ CASTRO. Depoimento. Memórias do Chumbo (Argentina), 04’45".
} 
mesma luta, por descobrir onde estavam seus netos desaparecidos em circunstâncias parecidas.

O filme aposta no trabalho de memória de segunda geração, a pós-memória, contando a todos nós as agruras da reconstrução dos vestígios e da história dos pais, que não foram conhecidos e que somente por meio dos testemunhos de amigos, familiares e companheiros de militância, seria possível conhecer e se reconhecer naquelas histórias. Como Mariana era apenas um bebê ao ser sequestrada, não possui memória daquele horror, e o filme salienta o quanto foi difícil para ela compreender o mal que se acometeu sobre sua vida, pois a família adotiva lhe transmitiu o afeto necessário ao desenvolvimento natural de uma criança. Esse complexo jogo de memórias será bastante destacado, pois para a moça, não haveria motivo para questionar a ação dos pais adotivos, pelo contrário, como julgar pais extremamente amorosos? Como aceitar que sua vida estava sendo colocada em cheque, sendo revirada do avesso e que tudo isso era para resgatar sua história, sua identidade. Mariana custou a compreender e será muito difícil entender algo diferente. Sua busca por sua história e de seus pais, recupera a dificuldade e as agruras da pós-memória, como destaca Beatriz Sarlo:

No caso dos desaparecidos, a pós-memória é tanto um efeito de discurso como uma relação particular com os materiais da reconstituição; com os mesmos materiais se fazem relatos decepcionantes e cheios de furos ou reconstituições precárias, que, no entanto, sustentam algumas certezas, embora inevitavelmente permaneçam os vazios daquilo que não se sabe. Mas isso o que se desconhece não é um efeito da memória de segunda geração, e sim uma consequência do modo como a ditadura administrou o assassinato. ${ }^{21}$

Vimos que no caso da menina Mariana Zaffaroli todas as relações são conflitivas, pois envolve espaços distintos, como ser uruguaia e/ou argentina, ter uma cultura, apesar de muito próxima, muito distante. Além disso, sua família está em dois lugares diferentes que representam formas distintas de encarar o horror das ditaduras, tanto no Uruguai, quanto na Argentina. 0 desaparecimento e morte dos pais de Mariana já envolve a correlação entre essas duas ditaduras, pois nos parece que o processo de sequestro e desaparecimento dos militantes estava articulado a uma inteligência colaborativa entre os dois países, e nessa época a

${ }^{21}$ SARLO. Tempo passado, p. 113. 
Operação Condor estava em fase de implantação, mas o acordo de cooperação entre as ditaduras, já existia, antes mesmo do compromisso de coalizão. 0 filme não trata somente dessa forma de colaboração, ele explora também o caso de um casal de brasileiros que foram presos em Buenos Aires e ficaram por lá, por conta da conivência entre as ditaduras, quando já vigorava a Operação Condor.

As garras do Condor estão afiadas e o terceiro filme da série trata de recuperar a história do Uruguai ligada ao futebol, articulada a cultura literária, já que um dos centros argumentativos deste filme é a figura de um dos escritores mais consagrado do Uruguai, Eduardo Galeano, que desde o início reflete sobre como é possível um país, que hoje é reconhecido como um dos países mais tranquilos do mundo para se viver, possa ter vivido anos sombrios com a ditadura e ter se tornado

Não quero identificar meu país como uma imensa câmara de tortura como foi o Uruguai daqueles anos. Na verdade, a proporção de desaparecidos na Argentina foi muito maior que no Uruguai. 0 roubo de bebês também foi muito maior na Argentina do que no Uruguai. E até os mortos que caíram fuzilados no Chile também foram em maior número do que no Uruguai. Mas o Uruguai foi o campeão sul-americano da tortura. E esse país chegou a ter a maior proporção de torturados de toda a América do Sul.22

O escritor uruguaio recupera experiências notabilizadas por cartas anônimas recebidas no exílio, na Espanha, as quais descreviam como a ditadura uruguaia construiu uma maquinaria de tortura e medo. Segundo Galeano, a carta que mais lhe impressionou dizia:

E uma das cartas que jamais esqueci dizia: "Você não pode nem imaginar o que é o Uruguai de agora. Essa é a capital do medo. Incrível. Incrível. Eduardo, isto é horrível. Somos obrigados a mentir ou a calar. Ou você cala, ou você mente, então a mentira está se convertendo na linguagem cotidiana das pessoas. Porque ninguém pode dizer o que pensa na verdade". Nesse reino da mentira, a tortura desempenhou um papel fundamental e uma carta dizia: "Acostumar-se a viver mentindo é muito difícil, é muito duro. Mas, bem pior do que mentir é ensinar a mentir, e eu tenho três filhos". Eu nunca esqueci essa carta porque é o melhor resumo do que foi aquele período no meu país. ${ }^{23}$

${ }^{22}$ CASTRO. Depoimento. Memórias do Chumbo (Uruguai), 01'30".

${ }^{23}$ CASTRO. Memórias do Chumbo (Uruguai), 06'15". 
A descrição de Galeano nos mostra que no Uruguai a sensação de controle e o poder do terrorismo de Estado foram avassaladores, tomando conta de setores inimagináveis, como destaca Geraldo Caetano. O controle foi tamanho que a ditadura chegava a vetar pessoas de esquerda que estivessem nas equipes de bairro, até influenciar nas eleições dos grandes times da primeira divisão. Mas o principal tema será a intervenção em um clube em especial o Defensor, clube pequeno que realiza um feito em 1976, desbanca os gigantes Nacional e Peñarol, e se sagra campeão uruguaio. Entretanto, vencer o campeonato por si só não o faz um clube diferente, a diferença se deu quando descobrimos que vários atletas do Defensor, inclusive o técnico, eram de esquerda e sofreram grande controle, ao ponto de um de seus principais atletas, Pedro Graffina, ser retirado do time pela ditadura, quando o Defensor teve que ir a Buenos Aires jogar a Copa Libertadores. Como lembra o historiador e ex-atleta do Defensor, Geraldo Caetano, "tiraram o passaporte dele e o impediram de viajar porque tinha antecedentes como homem de esquerda, como homem do partido comunista". ${ }^{24}$ Este não foi um caso isolado, Julio Filippini, no final da partida, ao ser entrevistado dedica o gol a seu irmão e aos companheiros da Prisão. Vejamos como internamente se construía essa imagem revolucionária do clube:

Recordo que De León insistia muito nessas imagens. "Defensores é a rebeldia". E, para nós alguns traduziam isso ideologicamente, outros, não. Mas todos podíamos nos juntar nessa ideia de que de alguma forma estávamos mudando a história e estávamos gerando um sinal de rebeldia. ${ }^{25}$

O filme propõe uma reflexão sobre como Uruguai, na figura do Defensor, fez resistência ao autoritarismo no futebol, mesmo diante da forte repressão contra a sociedade uruguaia e uma política de medo e tortura. A ascensão de um clube, que venceu os grandes e tradicionais, representa o desenvolvimento da esquerda como parte da necessidade de fazer a revolução e ser a rebeldia.

Sem dúvidas, o controle dos rebeldes, dos subversivos, não foi uma ação promovida excepcionalmente pelo Uruguai, foi uma política pensada muito longe, nos EUA, como vimos na estruturação da Operação Condor. Essa aliança latinoamericana ficou evidente também no caso do Chile. 0 quarto filme inicia com as 
imagens do encontro nos EUA dos presidentes brasileiro e americano, na Casa Branca, em que o presidente Emílio Garrastazu Médici, discursa para o presidente Richard Nixon, sobre "a fé no que havemos de construir juntos para o bem-estar dos nossos povos e confiança comum na causa da justiça, do progresso e da paz". ${ }^{26} 0$ filme constrói seu argumento em torno do importante papel do Brasil na deflagração do golpe militar no Chile, como destaca Heraldo Munõz, e explicita detalhes da associação entre os militares chilenos, os brasileiros e os norte-americanos:

A ditadura brasileira foi parte do movimento, que os EUA [sic] pressionou a derrubar o governo de Salvador Allende, governo socialista, eleito democraticamente. Nessa época o governo brasileiro com o Nixon, na Casa Branca, fizeram uma sorte de coordenação para ajudar o golpe. De fato, os documentos que agora se conhece revela claramente a coordenação entre a ditadura brasileira na época e a Casa Branca, sobre o presidente Nixon. Infelizmente o embaixador do Brasil no Chile foi parte do complô, foi parte da conspiração, pelo fato dos militares, que estavam planejando o golpe, reunirem-se na embaixada do Brasil em Santiago, o Embaixador Câmara Canto. ${ }^{27}$

A participação brasileira não se limitou a articulação do golpe, vários sobreviventes depuseram sobre a participação de agentes brasileiros participando das ações de repressão e das sessões de tortura, como descreve Alberto Gato Gamboa, sobrevivente do Estádio Nacional, que se tornou centro de prisão e tortura, o principal campo de concentração chileno.

O que eu recordo, pelo menos que aconteceu comigo é que os interrogadores argentinos e brasileiros eram mais incisivos, mais diretos, era com se tivessem mais experiência. Interrogavam e iam direto ao que queriam. Os chilenos ficavam enrolando até chegar ao que para eles era mais importante. ${ }^{28}$

As relações do Estádio Nacional com a repressão latina - tínhamos brasileiros, argentinos e quiçá uruguaios envolvidos nas sessões de tortura reforçam a aliança entre as ditaduras. Os diversos episódios ali ocorridos serão destaque no documentário. Entre eles teremos o jogo entre Chile e URSS, decidindo a vaga para a Copa de 1974, na Alemanha, em que o Chile inicia o jogo, sem seu adversário, e faz um gol, como exigiu a FIFA para validar o jogo, que foi realizada

${ }^{26}$ CASTRO. Memórias do Chumbo (Chile), 0'48".

${ }^{27}$ CASTRO. Memórias do Chumbo (Chile), 2'35".

${ }^{28}$ CASTRO. Memórias do Chumbo (Chile), 10'44". 
no mesmo espaço em que presos políticos foram torturados e mortos. Mas para além da encenação, o Brasil teve importante participação nesse dia, pois após a pseudopartida, o pior ainda ocorreu. Em meio à certeza dos presos e torturados, 0 Santos, clube brasileiro de maior prestígio na época, fará o jogo amistoso, em que ganhará da seleção chilena de cinco a zero.

No fim das contas não sabemos o que foi mais patético, se foi a encenação de jogo entre Chile e URSS, ou a aceitação do Santos em fazer parte daquela palhaçada. Certamente para o governo chileno e para seus aliados, a vitória e classificação para a Copa de 1974, sobre os soviéticos, se tornou uma vitória capitalista, antes mesmo de uma vitória da ditadura.

\section{INCONCLUSOS}

O caminho traçado neste trabalho foi tão somente para mostrar que existem no mundo do futebol aspectos pouco compreensíveis, mesmo quando se trata de eventos organizados por entidades consideradas independentes como a FIFA (Fédération Internationale de Football Association) e CONMEBOL (Confederación Sudamericana de Fútbol). Ficou bem claro que durante os tempos do Condor nada estava livre, o controle estatal foi absurdo e colaborou com diversas situações que deveriam ficar muito longe do futebol ou de qualquer outro esporte, mas se tornaram uma prática: manipulação, censura, prisões, tortura, conluios, perseguições. Gostaríamos de ter analisado somente as experiências de resistência neste trabalho, mas é preciso e é fundamental colocar algumas cartas na mesa, mesmo que essas cartas pareçam verdadeiros cartões vermelhos para os bastidores do futebol nos tempos do Condor. 


\section{REFERÊNCIAS}

COMISSÃO NACIONAL DA VERDADE. Relatório. Conexões Internacionais: A aliança repressiva no Cone Sul e a Operação Condor (capítulo 6), v. I. Brasília: dezembro de 2014.

McSHERRY, J. Patrice. Los Estados depredadores: la Operación Condor y la guerra encubierta en América Latina. Ediciones de la Banda Oriental, Montevidéu, 2009.

PALMAR, Aluízio. Onde foi que vocês enterraram nossos mortos? Curitiba: Travessa dos Editores, 2006.

PIRES, Breiller. Os 100 anos de João Saldanha, o técnico que atormentou a ditadura militar. El País. Esportes (Brasil), 03/06/2017. Disponível em: https://bit.ly/2KzfjLM.

REIS, Ramiro José dos. Operação Condor e o sequestro dos uruguaios nas ruas de um porto não muito alegre. Universidade Federal do Rio Grande do Sul, 2012. Disponível em: https://bit.ly/2jJ0j2x.

SARLO, Beatriz. Tempo passado: cultura da memória e guinada subjetiva. Trad. Rosa Freire d'Aguiar. São Paulo: Companhia das Letras. 2007.

FILMES E VíDEOS

CASTRO, Lúcio. Memórias do Chumbo: o futebol nos tempos do Condor (Brasil), TV ESPN, 2013. Disponível em: https://bit.ly/2jMh39g.

CASTRO, Lúcio. Memórias do Chumbo: o futebol nos tempos do Condor (Argentina), TV ESPN, 2013. Disponível em: https://bit.ly/YTGtVY.

CASTRO, Lúcio. Memórias do Chumbo: o futebol nos tempos do Condor (Chile), TV ESPN, 2013. Disponível em: https://bit.ly/1ASAhZV.

CASTRO, Lúcio. Memórias do Chumbo: o futebol nos tempos do Condor (Uruguai), TV ESPN, 2013. Disponível em: https://bit.ly/1qUd7TQ.

SALDANHA, João. Entrevista. Programa Roda Viva, TV Cultura, 25/05/1987. Disponível em: https://bit.ly/2KLVMsm. 